\title{
Espacios y sentidos de la participación juvenil
}

\author{
Alfredo Ghiso C., Paola Andrea Gaviria C., \\ Nataly Botero G.
}

\begin{abstract}
Resumen
El texto es una elaboración reflexiva sobre los resultados de un proceso de investigación formativa realizado con jóvenes del departamento de Antioquia, Colombia. En él, se plantean tres asuntos: la contrastación entre realidad/conceptos relacionados con la "condición de juventud", los modos en los que los jóvenes de la región leen sus oportunidades personales y sociales para enfrentar su contexto, y los sentidos que están configurando de político en sus prácticas y ejercicios de poder, así como en los espacios sociales donde actúan y se expresan.
\end{abstract}

Palabras clave: Moratoria juvenil, condición de juventud, lectura de oportunidades sociales, espacios y sentidos de la participación juvenil.

\begin{abstract}
This article is a reflective elaboration on the results of a process of an instructional investigation carried out with young people of the department of Antioquia, Colombia. Three subjects were considered: the contrast between reality/concepts related to the "condition of youth", the ways in which the local young people read their personal and social opportunities to face their context; concluding with their views deriving from politics in its practices and exercises of power, as well as in the social spaces where they take action and express themselves.
\end{abstract}

Key words: Youthful moratorium, condition of youth, reading of social opportunities, spaces and senses of the youthful participation.

Alfredo Ghiso C. Docente investigador, Facultad de Ciencias Sociales y Humanas Universidad de Antioquia, Coordinador del Laboratorio Universitario de Estudios Sociales Funlam. Coordinador del Proyecto de investigación formativa. alfredogh@epm.net.co

Paola Gaviria C. Socióloga, Co-investigadora.

Natalí Botero G. Socióloga, Estudiante en pasantía de investigación. 


\section{Introducción}

El texto tiene su origen en el proceso de investigación formativa desarrollado con jóvenes de los pregrados de trabajo social y sociología, en la Seccional Oriente de la Universidad de Antioquia, Colombia, a lo largo del 2005 y del primer trimestre del 2006. El equipo de investigadores buscó realizar una "Caracterización sociocultural, política y económica de los jóvenes y de su participación organizada en la construcción y aplicación de políticas públicas municipales" ${ }^{\prime 1}$ con la finalidad de conocer si es posible tender puentes entre los movimientos juveniles y las entidades encargadas del diseño y ejecución de las políticas públicas de juventud, procurando desestigmatizar a los jóvenes y aportar a su reconocimiento y valoración además de abrir espacios para comprender las oportunidades de empoderamiento, canalizar y potenciar su participación en los ámbitos donde se decide su futuro y el de los municipios que habitan.

La investigación se desarrolló en el departamento de Antioquia, ubicado en el noreste de Colombia y dividido, a su vez, en nueve sub-regiones con contextos geográficos, demográficos y sociales diversos. Una de ellas es la del Oriente Antioqueño, conformada administrativamente por cuatro zonas: Embalses, Páramo, Bosques y Altiplano. Esta última también es conocida como Oriente Antioqueño Cercano por sus relaciones comerciales y en general por la influencia que la Ciudad de Medellín tiene sobre la zona. Se trata de una región geográfica estratégica y privilegiada para el desarrollo de Antioquia y el País, pues abastece el 35\% de la energía hidroeléctrica de Colombia, es asiento de un importante complejo industrial y una moderna estructura de comunicaciones, además de su riqueza en biodiversidad, potenciada por la variedad de climas y pisos térmicos que van desde los territorios

1 Proyecto: Caracterización sociocultural, política y económica de los jóvenes y de su participación organizada, en la construcción y aplicación de políticas públicas municipales. Carmen de Víboral, Facultad de Ciencias Sociales y Humanas, Departamento de Trabajo Social, Seccional Oriente, U. de. A. 
más cálidos hasta los paramos más fríos, cualidades que la hacen propicia para investigaciones biogenéticas y ecoturismo rentable. Durante las últimas décadas, la sub-región ha sido escenario de conflictos sociales y armados. En el último lustro, han sido perpetradas más de un centenar de masacres y miles de familias han sufrido el desplazamiento forzado, no solo por la violencia de los combates, sino también por las condiciones de pobreza y abandono, tristes legados de más de una década de guerra. La lucha se hace cada vez más intensa y la zona es campo de batalla para los diferentes actores armados (Uribe, 2000:3).

El estudio se realizó con jóvenes de la región del Oriente Antioqueno Cercano, en los municipios de Rionegro, La Ceja, Guarne, Marinilla, El Retiro y el Carmen de Viboral. En ellos, los jóvenes constituyen aproximadamente el 35\% de la población total, compuesta por hombres y mujeres en partes iguales. El 64\% de estos jóvenes vive en la zona urbana y el 36\% restante en la zona rural.

Una de las principales herramientas empleadas en la investigación fue la encuesta aplicada a 554 jóvenes de los seis municipios cuyas edades estaban comprendidas entre los 12 y 29 años de edad. De la muestra de jóvenes encuestados, la mitad tiene entre 18 y 23 años, otro 30\% tiene entre 12 y 17 y el 20\% restante está entre los 24 y 29 años de edad. En cuanto a la educación, el 61\% de los jóvenes que participó en la encuesta se encontraba estudiando en el momento; de estos, el 5\% había cursado únicamente la básica primaria, otro 29\% había llegado hasta la básica secundaria, el 43\% había logrado una acreditación de media vocacional o técnica y solo el 16\% había alcanzado un nivel universitario. La mitad de los jóvenes que se encontraban estudiando eran mujeres. El 45\% de los jóvenes encuestados tenía empleo, mientras que el 55\% no. Aunque las mujeres alcanzaban mayores niveles de estudio, la mayor parte de los encuestados que se encontraban trabajando eran hombres. Es de notar que los ingresos del 53\% de los jóvenes provienen de la familia y reciben aproximadamente el equivalente a treinta y dos dólares (US\$ 32) mensuales. 
Pasando a las características de la participación juvenil en el Oriente Antioqueno Cercano, según datos de la encuesta realizada, un amplio porcentaje de jóvenes, el 69\%, declaró no hacer parte de ningún grupo juvenil, aun cuando las opciones comprendían grupos religiosos, artísticos, deportivos, académicos, políticos, ecológicos y armados. El 31\% restante hacía referencia a quienes sí participaban en algún grupo. De ese porcentaje, el 13\% estaba asociado a grupos deportivos, el 7.4\% a grupos artísticos, el $4 \%$ a grupos religiosos y el $6 \%$ restante a grupos ecológicos o académicos. La afiliación a grupos políticos solo llegaba al $0.4 \%$ del total de jóvenes encuestados. Frente al tema de la participación en las elecciones, el $60 \%$ no votó en los últimos comicios, mientras que el 40\% sí participó en el proceso electoral. Al preguntarles a los jóvenes sobre sus reacciones frente a la realidad política del País, el $55 \%$ respondió con cuestionamiento, el $26 \%$ con indiferencia, el $10 \%$ con compromiso y el $9 \%$ con miedo. También se preguntó a los jóvenes si sabían de la existencia de una política de juventud, pero el $73 \%$ declaró que no la conocía, mientras que el $27 \%$ sí estaba enterado de su existencia. Del total de los jóvenes consultados en la encuesta, el 95.5\% no estaba participando en la elaboración de la política pública de juventud de su municipio.

Teniendo en cuenta el anterior marco descriptivo, en este artículo nos proponemos presentar tres reflexiones: una surge en torno a la contrastación realidad/conceptos relacionados con la condición de juventud, que como lo afirma Dina Krauskopf: "fue fijada a partir de una regulada secuencia de eventos y una imaginaria homogeneidad social (cercana a la clase media). La homogenización de la percepción oficial de la juventud se caracteriza por la debilidad en el enfoque de género, cultura, etnia, referencia rural-urbana y estrato económico" (Krauskopf 04: 27). En la segunda parte, se expondrá cómo, desde las condiciones heterogéneas y desiguales, los jóvenes de los municipios investigados leen sus oportunidades sociales y enfrentan su realidad, configurando diversas trayectorias vitales. Antes de pasar a las conclusiones, se plantearán los sentidos críticos que los jóvenes 
están recreando de lo político en sus ejercicios de poder y en los espacios sociales donde actúan y se expresan. El apunte concluye con una serie de afirmaciones que, a manera de hipótesis, quieren propiciar el debate y abrir nuevas rutas de reflexión y acción investigativa.

El texto que presentamos puede ser leído como una elaboración sobre los resultados de un proceso de investigación formativa; con él pretendemos buscar caminos que permitan debatir los discursos, los sentidos, las perspectivas y las posibles articulaciones que posee el conocimiento sobre las múltiples formas de ser joven en Latinoamérica.

\section{Nombrando realidades juveniles}

¿Cómo nombrar la realidad juvenil de la región del Oriente Antioqueño?, ¿con qué conceptos?, ¿qué es posible comprender desde ellos?, ¿desde qué tradiciones teóricas?, ¿qué nombran y visibilizan?, ¿qué no se revela y se oculta? Estas son preguntas que nos hicimos a lo largo del proceso de investigación, partiendo de un reconocimiento fenomenológico en el que la condición de juventud se reconoce como "una manera particular de estar en la vida: potencialidades, aspiraciones requisitos, modalidades éticas y estéticas, lenguajes" (Margulis, Urresti 98, 4). Pero, es de notar que esta condición sociocultural no es ni se ofrece de igual manera a todos los jóvenes, puesto que "el tiempo de ser joven identitariamente varía entre estratos, culturas y clases sociales. La mayoría de las personas menores de edad de la región latinoamericana, que viven en la exclusión, son invisibilizadas como tales y enfrentan una premura psicosocial en el cumplimiento de responsabilidades, supuestamente adultas y con ausencia de oportunidades" (Krauskopf 04, 27).

Desde la investigación, se han descrito e identificado diferentes formas de ser joven en la región, caracterizadas por trayectorias socioculturales, políticas y económicas diversas que permiten confrontar las lecturas homogenizadoras que educa- 
dores, políticos y administradores han elaborado acerca de la condición de juventud en la zona. Por ello, se han caracterizado experiencias significativas que dan cuenta de modos de resolver, decidir, organizarse, entender y sentir problemas y realidades de su entorno; se trata de vivencias en las que descubren las oportunidades y restricciones subjetivas y contextuales. Así, ellos van configurando lo que son y de dónde son, lo que les impone tomar decisiones frente a lo religioso, lo político, lo formativo, las relaciones de pareja, las opciones sexuales, los consumos y a las actividades relacionadas con el uso del tiempo libre.

El tiempo y el espacio, reales o virtuales, tejen la "condición de juventud" en esta región, resaltando ideales, destacando aconteceres y prototipos, definiendo presencias y ausencias en la vida de los jóvenes. Muchos asumen un camino "postfigurativo" en el que los jóvenes aprenden primordialmente de sus mayores, el tiempo es repetitivo y el cambio social lento, responden a patrones culturales ancestrales y su futuro no parece distar mucho del pasado de sus abuelos: peones agrícolas, comerciantes minoritarios, obreros en las fábricas o cultivos de flores de la región. Otros asumen como vías configuradoras las dinámicas y desafíos del presente y de su entorno cercano; sienten que tienen que prepararse, estudiar, ser alguien en la vida, distinto, si es posible, al modelo que tienen de sus padres o hermanos mayores. "Una orientación en función de la carrera profesional adaptada a la competencia por conseguir buenos puestos" (Beriain 96: 209).

"Yo soy hijo de campesinos pero no soy campesino, yo me crié en lo urbano ya; soy el hijo elegido de una familia de cinco muchachos (risas), para estudiar en la universidad, para "educarme en la universidad". Ellos recibieron ese apoyo, pero cada uno en su cuento, cada uno en sus cosas. Por ejemplo, mi hermano y yo tuvimos la misma educación en el mismo colegio, un colegio de costumbres católicas con su lema de "buenos cristianos, honrados ciudadanos"; mi hermana en un colegio 
de monjas pero todos siguieron su camino (...) Como te digo, en mis hermanos eso no influye y en mucha gente no influye, porque también piensas en otras cosas, uno tiene no conciencia de clase, pero sí conciencia de lo que sucede, porque ellos no han tenido acceso ni siquiera a la lectura, televisión, radio, además de lo que irradian ciertas personas de la calle. Lo mismo pasa con nosotros, nosotros de alguna manera criticamos ciertas cosas pero hacemos parte de ese mismo sistema; no nos podemos desprender, lo más radical sería llegar y abrirnos para el campo...." 2

En la región también se identifican los jóvenes que tejen su condición de una manera "prefigurativa", donde el "futuro deja de ser el eje ordenador del presente y son las condiciones del presente las que permiten dar pasos que vayan construyendo el futuro. La calidad del presente es un factor determinante en la posibilidad de que los jóvenes proyecten su quehacer con esperanza" (Krauskopf, 04: 32). Esto no se realiza al margen de los grupos de pares con los que comparten las mismas leyendas, gustos, consumos, ambientes y prácticas ${ }^{3}$.

"Más que amigos somos como hermanos. Llegamos al taller y no decimos "vos tenés tanto y yo tengo tanto", sino que decimos, "tenemos tanto"; si el uno tiene mil y el otro tienen diez mil, entonces entre todos tenemos once mil y si con esos once mil nos alcanza para media de guaro, vale; y si no tenemos sino tres mil y con eso nos alcanza para tinto, entonces tinto. Es el compartir y es el poder estar con el otro (...) Como no nos reunimos todos los días sino cada ocho días, entonces tenemos que contar, cosas que decirnos, hay una alegría de encontrarnos, motivos de sonreírse y de reírse, del uno y del otro,

2 Entrevista 1: La Ceja, febrero, 2006.

3 Las categorías "postfigurativa" y "prefigurativa" son tomadas de Mead, Margaret (1971) Cultura y compromiso. Garnica; Barcelona. 
en el buen sentido de la palabra, porque no se trata de burlar o de mofar, pero sí se trata de pasar bueno. Un gran respeto por el otro, una camaradería, siempre son las risas, las bromas, el chiste, el chisme, las anécdotas, y que nos confluye algo, la pasión por la literatura, por eso estamos ahí."

Aunque en algunos jóvenes se da una deslocalización temporo/espacial que confunde tiempos valorando solo el instante presente, la "condición de juventud" más que una posición, circunstancia o situación es esa dinámica donde el espacio, el tiempo y sus interacciones permiten a los jóvenes de la región configurar múltiples trayectorias vitales; donde las posibilidades y oportunidades tienen que ser identificadas, valoradas por ellos con relación al pasado, al presente joven o al futuro adulto y convertidas en sus propias expresiones sociales, políticas o culturales.

\section{Trayectorias Vitales}

Así como en la región existen jóvenes que pueden recuperar sus legados y dar cuenta de ellos, también hay otros que participan de una condición de juventud caracterizada por la vulnerabilidad, el riesgo social y cultural de ser desheredados de toda pertenencia sea esta material o simbólica. Una parte de este segmento de la juventud se caracteriza por estar a merced de los modos y modas que propone el mercado.

“... ubicaron sus casas, sitios de rumba como el Mall, algunos bares y lugares de comidas en San Antonio.... se reúnen mucho en las fincas de sus amigos a hacer asados o fiestas. ...lo que al municipio le falta es un centro comercial. $^{\prime 5}$

En estos espacios, los jóvenes actúan como mercancías, se exhiben, se muestran, se ofrecen:

4 Entrevista 2: Marinilla, enero 2006.

5 Registro etnográfico Rionegro, junio 2005. 
“...en el Mall siempre es la misma gente, la misma "pasarela", la gente que va abre las puertas de su carro, pone la música a todo volumen y se dedica a tomar licor; las conversaciones que allí se dan son tontas, no hay nada más para hacer". ${ }^{6}$

En el mundo de las pasarelas, las modas, las marcas, los rostros bellos y los cuerpos perfectos, no tienen lugar, identidad o pertenencia aquellos que no poseen los patrones del estereotipo. Muchas mujeres jóvenes consideran que solo si se parecen a las modelos pueden ser reconocidas e incluidas en los grupos de pares:

"Recuerdo que en esa época mi contextura era robusta, era una chica poco atractiva, salía los sábados en la noche a las discotecas de Llanogrande $y$, al ver tantas mujeres hermosas, me sentía muy mal, triste, fea, despreciable... Tomaba mucho licor hasta embriagarme y, al día siguiente, en mi casa, para no sentir la tristeza, ingería somníferos que me hacían dormir toda la tarde y olvidarme de mí misma... Recuerdo que también me volví obsesiva por cambiar la constitución de mi cuerpo, así que solo comía en todo el día dos frutas; otras veces, cuando comía, vomitaba... Todo terminó un día en el que sentí que moriría, mis manos y mis pies no me respondían, no podía ni siquiera levantarme de la cama... en mi familia nadie se enteró de lo sucedido..." ${ }^{77}$

Pero no todos los jóvenes de la región siguen modas. Algunos se inquietan por identificar lo que hay detrás es esos estereotipos y desconfían de aquellos que aparecen como modelos neutros, sin intereses ni opiniones. La actitud crítica llega al desprecio de esas formas de vidas formateadas, uniformes y por sobre todo impuestas.

$6 \quad$ Ibid.

7 Registro etnográfico Rionegro, enero 2006. 
“Los representantes son unos aparecidos ¿Qué más pensar de esos manes? A lo bien, son de esos aparecidos que uno alguna vez vio, que alguna vez conoció, uno dice ve, yo a este man tal vez lo vi en tal lugar, pero uno no sabe absolutamente nada de lo que ellos son y de los intereses que tienen. Por ejemplo, si tiene corbata, no, definitivamente... suena despectivo, pero si tiene corbata es porque tiene una actitud de vida desde mi punto de vista despreciable, no él como ser despreciable sino la forma de vida que tiene porque es una forma de vida impuesta y que pertenece a esos modales y a esa diplomacia entre ciertas elites intelectuales y ejecutivas; hacen parte de esa uniformidad que le inculcan a uno en la escuela, la camiseta por dentro, lleve el uniforme, lustre los zapatos..."

La expresión de esta inconformidad se pone de manifiesto en las prácticas de creación y apropiación cultural de algunos jóvenes de la región, cuando a partir de un análisis de lo que les ofrece el mercado prefieren actuar sobre los modos de pronunciarse y los contenidos de sus expresiones. No es raro que entonces se configuren expresiones contraculturales que se posicionan de una manera radical en contra de los parámetros que impone el estado, la sociedad adulta y autoritaria.

“Prima más la idea que la música; lo más importante es la transmisión del mensaje, pero definitivamente la música, como una de las manifestaciones artísticas para nosotros, también es bien trascendental; es también ir en contra de cierto cánones que el mismo comercio se ha encargado de establecer frente a la música, y afinamos y listo, no puedo decir que somos lo más desafinado del mundo, pero es una estética diferente a la que se pueda manejar en la música de mercado." 9

8 Registro etnográfico El Carmen, febrero 2006.

9 Registro etnográfico Rionegro, junio 2005. 
Otras interacciones resignifican la condición de juventud en los espacios y tiempos de las instituciones educativas; allí los jóvenes configuran sus trayectorias vitales como transitoriedad preparatoria; disponiéndose para un futuro.

“Es un lugar al que tengo que asistir así no quiera, porque este es necesario, a veces lo siento como una obligación. ${ }^{\prime 10}$

En estos espacios se ajustan a la norma, aprendiendo a no cuestionarla o modificarla;

“Las Instituciones educativas se creen como espacios aislados; ven nuestro desempeño como estudiantes y lo evalúan sin tener en cuenta que nosotros también somos hijos, somos hermanos, somos amigos pertenecemos a una gran sociedad". ${ }^{11}$

En esta transitoriedad preparatoria, las responsabilidades sociales y políticas parecerían restringirse a los espacios sociales escolares. Allí, bajo la tutela de maestros y profesores, se ejercitan en elegir democráticamente sus representantes, participar en consejos estudiantiles y ocupar jerarquías conforme lo establecen los reglamentos con los que operan las instituciones educativas. Algunos jóvenes se muestran interesados en promover mecanismos de participación que les permitan integrarse desde sus formas de expresión, sus necesidades y actividades.

“Los estudiantes han propuesto a la rectora utilizar los aparatos de que dispone el colegio para implementar una emisora interna en los descansos; pero ella lo impide con el argumento de que eso es perder el tiempo de escolaridad, asimismo pasa con sus deseos de elaborar un periódico mural, o de realizar actividades con el fin

10 Registro etnográfico Marinilla.

11 Registro etnográfico Marinilla. 
de recoger fondos para la fiesta de grados de los estudiantes de once" ${ }^{\prime 12}$

En muchos casos, la transitoriedad preparatoria aparece como una moratoria discursiva, intelectual, en la que los jóvenes saben muchas más cosas y poseen un mayor nivel educativo que los adultos; tienen un conocimiento de dispositivos sociales y culturales -derechos, normas, leyes, criterios- y de tecnologías de la información y la comunicación, que no ponen en juego a la hora de actuar para conseguir sus propósitos; porque, según ellos, se topan con murallas que les cierran la posibilidad de una práctica comunicativa de negociación que les impide la toma de decisiones, frustrando o inhibiendo las actuaciones o proyectos de acción. Esta falta de eficacia "da rigidez y agrava las respuestas de los mayores, devalúa las capacidades juveniles, incrementa la discriminación etaria y el apoyo en el control externo" (Krauskopf 04, 37).

La acción política, cultural, y las decisiones en el ámbito de sus municipios se ven como algo del futuro, y que no hacen parte del presente. En el ahora, lo que les toca es prepararse para tomar decisiones en el futuro; el problema radica en que tanto la preparación como las experiencias están marcadas por representaciones sociales subordinadas a una cultura política autoritaria, clientelista y claramente elitista. Estos ejercicios parecen aislar a los jóvenes en una serie de prácticas marginales, donde, en francos simulacros, agotan las responsabilidades sociales.

Así, el repertorio de prácticas sociopolíticas se estrecha en las instituciones educativas porque solo les permiten espacios discursivos donde exponer sus demandas para equilibrar los deberes con los derechos y lograr permisos para el uso indiscriminado de accesorios como manillas, piercings, aretes, teléfonos celulares o discutir el porte o no del uniforme escolar. Estos son los moti-

12 Entrevista 7 enero 2006. 
vos que llevan habitualmente a la confrontación del joven con el adulto y la institucionalidad.

“Las normas surgen en el colegio. Cuando tienen que solucionarse los conflictos, no hay normas construidas sino impuestas. Las normas siempre aparecen después. Uno se da cuenta de algunas cosas que no están permitidas después de que suceden. Generalmente, cuando alguno de nosotros va a solucionar un inconveniente con un profesor o coordinador dice que nosotros conocemos lo que se dice en el manual; eso no es cierto, muchos no conocemos el manual. Este lleva como 7 u 8 años sin modificar y yo me cuestiono por qué no me preguntan a mí cómo me parecen si yo estoy de acuerdo o no". ${ }^{13}$

Por fuera del colegio, la marginación de la población juvenil de los debates públicos y de la toma de decisiones da cuenta de la exclusión de los jóvenes. El anonimato, el tener que pasar inadvertido, el asumir que se debe optar por invisibilizarse hace parte de la vida cotidiana de muchos jóvenes del Oriente Antioqueño. Al mantenerse en este limbo, la exclusión parecen no sentirla, tampoco se resienten ante la estigmatización y desconfianza adulta e institucional; así, le hacen el quite al control y a la inseguridad que proviene de las diferentes entidades o actores armados (es de anotar que, en los municipios de la región, es común que exista un control de las actividades que los jóvenes realizan en espacios extra escolares por donde van uniformados; la mayoría de los municipios tienen toque de queda para los jóvenes y algunos grupos armados controlan vestimenta de las muchachas y el largo del pelo en muchachos).

Para muchos, esta forma de vivir la condición de juventud, desde la transitoriedad preparatoria anónima, normalizada, límbica, les permite sobrevivir en ambientes familiares, barriales y muni-

13 Entrevista 7 enero 2006. 
cipales sin hacerse mayores problemas, asegurando unas condiciones de vida donde los intereses básicos como el cuidado por el cuerpo, el look, el salir con amigos y amigas, el ver tele, el disponer de tiempo libre y seguro se garanticen. Este ocultamiento de lo público responde, entre otras cosas, a unas recompensas, a unos ingresos mensuales o semanales dinero para los gastos de estudio y transporte, mesadas semanales, confianza de los padres...

En la región del Oriente Antioqueño la mayoría de los jóvenes tienden a distanciarse de las instituciones y de las lógicas políticas formales; así vivencian la "moratoria política" como un paulatino y creciente proceso de distanciamiento, desencantamiento y desentendimiento de lo social y de lo político. Aunque muchos de ellos encuentran que la quietud y la inercia política están justificadas por la desconfianza en las formas tradicionales de ejercer poder, otros han asumido vencer la inmovilidad al organizarse y participar desde escenarios formales y alternativos.

La desconfianza en las instituciones y la escasa valoración de estos con respecto a los saberes juveniles los motiva a organizarse autónomamente, pero pocos sobrepasan con éxito los dispositivos de control de las instituciones públicas o de las organizaciones sociales tradicionales:

"Cuando llegamos a tener una responsabilidad, desconfían de nosotros"; "en las juntas de acción comunal nos encargan siempre de lo deportivo, no reconocen en nosotros otras capacidades". ${ }^{14}$

Los adultos actúan frente a los idearios, propuestas y contenidos juveniles cooptándolas, vaciándolas de sus sentidos originales y resignificándolas, especialmente cuando se trata de expresiones culturales y organizativas. Para las instituciones y adultos de la región, es una garantía de sosiego que los jóvenes no se metan en política y pongan sus esfuerzos en conseguir un buen

14 Registro etnográfico Rionegro, febrero 2006. 
puesto de trabajo que les garantice autofinanciarse los estudios y unos consumos para poder pasar los tiempos de ocio con sus amistades.

Estas condiciones contextuales, caracterizadas por la exclusión política y económica de los jóvenes y por la ausencia generalizada de su participación en los asuntos públicos, llevan a que se les limite y restrinjan los escenarios de acción y los dispositivos de diálogo y negociación con las instituciones, los empresarios, los actores armados, los educadores y los adultos. Por ello, en las relaciones que han entablado con la institucionalidad, estos jóvenes han experimentado sensación de suspensión de sus posibilidades de participar en lo público.

Por las razones anteriores, la mayoría de los jóvenes del Oriente Cercano se ha estancado en la quietud, el anonimato consumista y la exacerbación del presente. El entorno en el que se desenvuelven -familia, escuela y demás instituciones- ha arraigado en ellos la idea de que la participación política está referida únicamente a lo concerniente al Estado, a la representatividad y a ejercicios como la votación o la adscripción a partidos políticos.

Así todo, encontramos en la zona jóvenes inconformes que eligen resistir a la imposición de valores individualistas, al avance de la indiferencia, o a la manipulación de que son objeto por parte de las instituciones adultas, sometiéndolos al silencio y a la invisibilidad.

"La forma de vida que buscamos conseguir es una forma de vida que garantice el desarrollo de la individualidad; definitivamente no es algo individualista. Si bien va a estar toda esa parte del individuo ahí, debe ser para construir una posibilidad colectiva." 15

Desde las prácticas cotidianas, los discursos y las agrupaciones que conforman con sus pares, los jóvenes de la región atri- 
buyen nuevos sentidos a la política y al poder. Tal como afirma el sociólogo Ulrich Beck, "la otra cara de la individualización es la búsqueda de sentido, de un sentido susceptible de ser experimentado, vivido de forma activa y cotidiana, y conciliado con las formas de la propia vida" (Beck; 2002:180). Queda claro que esa individualización de la que se habla está relacionada más con la elaboración de sentidos que con el aislamiento. Por supuesto, esa exploración y confección de significados vitales incluye la dimensión política de sus acciones organizadas.

Las organizaciones juveniles conformadas desde el interés y la voluntad de los jóvenes y sus prácticas son vías a través de las cuales ellos canalizan y manifiestan sus perspectivas a futuro, sus opiniones sobre la realidad en la que viven, sus propuestas de cambio a los modelos establecidos y, en general, sus demandas sociales. Pero su actuar no se limita a dar a conocer sus visiones del mundo; los jóvenes de la región también actúan políticamente desde escenarios artísticos, académicos, religiosos, ecológicos, construyendo, desde planos diferenciados y alternativos, legitimidades sociales que aportan a la construcción de posibles cambios que, desde el presente, vayan transformando condiciones y escenarios de futuro.

Sus expresiones, lógicas y prácticas organizativas se anclan en terrenos culturales, deportivos, ambientales, artísticos, políticos, académicos y sociales; de esta manera, los jóvenes conforman grupos de música, corporaciones de teatro, grupos de investigación y de estudio, grupos dedicados a la literatura, grupos ambientales, y generan formas de expresión alternativa como los pasquines de circulación subterránea, entre otras. En estas diferencias, se resalta como rasgo principal su conformación autónoma, nacida de la voluntad de hacer algo, de sentirse útil, de identificar intereses comunes y afinidades ideológicas entre los miembros de las agrupaciones juveniles.

Las motivaciones que los estimulan a organizarse y a participar son diversas pero limitadas a los contextos locales y se con- 
figuran en espacios que se resisten a ser institucionalizados. Uno de los asuntos emergentes más relevantes es que los jóvenes integrantes de este tipo de grupos expresan un marcado interés por lo que han llamado realidad, no solo por conocerla, por manifestar sus puntos de vista, sus opiniones y sus propuestas a otros, sino también por actuar e incidir sobre ella desde diferentes terrenos y estrategias de acción.

“[...] el diario vivir es lo que más nos influye, es encontrarse por ejemplo que un día todos los de la banda no tienen empleo y no tienen nada de billete, y algunos, en ese momento, sin tener donde estar viviendo; entonces, esas mismas cosas son las que nos influencian; la misma lectura que hacemos de la realidad, yo creo que es el principal factor que influye."16

\section{Sentidos de la acción política juvenil}

En el proceso de investigación, se pudo reconocer que los sentidos, expresiones y proyecciones políticas de algunos jóvenes de la región subvierten y resignifican las representaciones e imágenes de las formas tradicionales de poder.

"[...] el poder como tal no lo vemos bueno y nos parece que corrompe (...) el poder daña a la gente, y puede tener las mejores intenciones del mundo, pero el solo hecho de tener poder te hace ciego, te hace pensar "yo tengo la razón". Sobre el ejercicio político, expresan que "la política es pura trama, engañan a la gente."17

En consecuencia, "lo político no aguanta". Frente al ejercicio político por representación, se refieren como unos "aparecidos que son siempre los mismos, que pertenecen a una misma élite o que se han ido formando ahí". Ese asunto de la representatividad

16 Entrevista $\mathrm{N}^{\circ} 5$, junio 2002

17 Entrevista 7, enero 2006. 
los cuestiona, pues “ ¿quién me va a representar a mí? ¿Quién va a representar a todos, todos tan distintos?". Estos juicios nos muestran una suerte de rechazo al ejercicio político tradicional en el que, según sus propias percepciones, "alguien manda y alguien obedece".

El tránsito que media entre el silencio y el levantamiento juvenil está signado por un reconocimiento personal en el que los jóvenes se asumen como sujetos sociales y políticos; por tanto, como sujetos que pueden decidir, organizarse y actuar. Dicha valoración es la que principalmente los conduce por caminos de acción y movilidad en esferas sociales, ambientales, políticas, académicas, artísticas y culturales. Gracias a ese reconocimiento, estos jóvenes son capaces de hacer lecturas de sus potencialidades personales y de las oportunidades que su entorno les ofrece. Pero valorar oportunidades no es lo único que se necesita para trascender la inmovilidad: estos jóvenes han advertido que las acciones organizadas son condición imprescindible de su empoderamiento. En este sentido, la organización es requisito esencial para configurar formas de participación independientes, pues, sin agruparse y organizarse con otros jóvenes, sin buscar afinidades, construir consensos, decidir qué acciones realizar y de qué forma hacerlo, ellos mismos se confinarían a la inactividad política o a los ejercicios de poder institucionales que tanto rechazan.

Los jóvenes crean, desde el discurso y las formas de nombrar, distinciones claras entre sus grupos y otros. Es una forma narrativa en la que ellos -poderosos- y nosotros -grupos de jóvenes- disputan intereses, ejercicios y lugares de poder.

“[...] el poder de ellos depende de la desorganización de nosotros" y que su propio poder "parte del reconocimiento, el poder de los grupos es porque están organizados, son organizados." 18

18 Registro etnográfico, octubre 2005. 
En concordancia con sus apreciaciones, es posible considerar sus organizaciones tal como lo conceptualizó Hannah Arendt, para quien la organización es "la capacidad del hombre para actuar y hacerlo junto y de acuerdo con otros" (Arendt; 1993:132). Esta noción integra toda clase de prácticas generadas por disposiciones comunes en un colectivo de personas y eso es precisamente lo que sucede con los grupos de jóvenes en quienes se ha basado el presente texto. Para los miembros de los grupos conformados autónomamente, sus niveles de empoderamiento son consecuencia directa de su organización. Esto implica ser consciente de que el empoderamiento juvenil es más efectivo si se construye con independencia de las instituciones, porque, para ellos, estos son sinónimo de riesgos como: la manipulación, la censura y el desconocimiento de la validez de sus propuestas.

Como se verá, los ejercicios de poder que practican estos jóvenes tienen características muy diferentes de los ejercicios tradicionales. En primer lugar, se trata de un poder interaccional que circula de uno a otro; ejercicio en el que los jóvenes rechazan las lógicas de representatividad y, en general, las expresiones binarias de autoridad y sumisión, obediencia. El menosprecio se expresa, más allá del discurso, en las formas organizativas de los grupos donde se privilegia la horizontalidad. La ausencia de jerarquías al interior de algunas agrupaciones juveniles es una cualidad que surge de rehusarse activamente a la verticalidad. Los jóvenes impugnan activamente las posiciones de abajo o de arriba tanto al interior de sus grupos como fuera de ellos.

“[...] en el grupo en el que estoy se tomó una decisión y fue que no había relaciones de poder, que simplemente no hay presidente, no hay nada, simplemente una organización horizontal y ya." 19

Al tratarse de ejercicios de poder que declinan la verticalidad, las posiciones que asumen los jóvenes incluyen compartir

19 Entrevista 10 febrero 2006. 
sus conocimientos académicos y construir lazos y acciones partiendo de los intereses y expectativas de otros en el presente.

“[...] ser parte de esa construcción; no nos interesa construir en sí, sino aportar nuestro granito de arena a esa construcción, desde los estudios o desde los conocimientos que tenemos; cómo vamos a apoyar para que la sociedad vaya construyendo ese futuro." 20

Son actos en los que presente y futuro se correlacionan. Para estos jóvenes, el presente no se escapa por planificar el futuro; al contrario, son conscientes de su potencial para modelarlo con otros, aunque sea un poco.

Otro rasgo distintivo de los ejercicios de poder de los jóvenes agrupados es que no parten de posiciones mesiánicas o de certidumbres. Para ellos, es necesario primero indagar por las realidades que los inquietan, ganar mayores niveles de comprensión y de conocimiento para luego decidirse a actuar.

"Se trata de cuestionar primero pero no para dar nosotros la respuesta; (...) ¿por qué?, ¿quiénes somos nosotros para decirle a otro: usted tiene que hacer esto? Seríamos demasiado pretenciosos, seríamos demasiado picados, muy chicaneros nosotros decir jah! Es que hay que hacer esto. Nosotros, ¿qué vamos a saber? Nosotros no sabemos." 21

Pero ¿Qué es lo que conecta estos grupos de jóvenes? ¿Qué los mantiene unidos a través del tiempo? La reciprocidad entre los miembros y la compatibilidad en las relaciones es otro de los sentidos políticos que los jóvenes han creado a lo largo de su permanencia en los grupos. Los afectos también se incluyen en las razones para permanecer agrupados, pues, a medida que el tiempo pasa y le salen al paso a las dificultades, van desarrollándose

20 Entrevista 6 enero 2006.

21 Entrevista 6 enero 2006. 
entre los miembros de los grupos sentimientos afectivos que van paralelos a sus quehaceres académicos, políticos, ambientales o artísticos. En relación con párrafo anterior, en el que se trató la horizontalidad en las relaciones, ser amigos los exime de la verticalidad.

“[...] más que amigos somos como hermanos. Es el compartir y es el poder estar con el otro. Es una camaradería, es una familia". Para otro de los jóvenes, "aparte de lo académico hay una amistad que se ha ido formando, creando, en el tiempo que lleva el grupo. Entonces empezamos a tirar para el mismo lado ideológico y fuera de lo académico, como todos somos muy compatibles ideológicamente somos muy tolerantes el uno con el otro, entonces también hay charlas, paseos, rumbas, fiestas, matrimonios, ya se caso una parejita del grupo... hay una amistad muy bacana, de verdad que se siente bien estar en el grupo." 22

Se plantean dos importantes elementos de cohesión entre los jóvenes agrupados. Primero, las afinidades ideológicas que se gestan a partir de sus experiencias e intereses comunes y, segundo, la diversión. Pero no se trata de una diversión vacua. Al contrario, está cargada de significados en la medida en que los grupos son conformados por amigos que conocen sus gustos y aversiones, que comparten las mismas pasiones y que incluso se quieren. Es una diversión plena de sentido que tiene efectos vinculantes entre los integrantes de los grupos, a través de los que se gestan nuevas relaciones y se sueñan nuevos proyectos. Por ejemplo, para los jóvenes músicos del Oriente Antioqueño, la diversión es una intención expresa de sus prácticas.

"Fuera de que te pone alegre, te hace cuestionarte bastante, hay críticas y hay sentimientos personales que ¡huy, como! (...) por eso digo que la música que nosotros

22 Entrevista 7 enero 2006. 
hacemos es para divertirnos y para ponernos a pensar a ver qué hacemos, qué podemos hacer frente a cualquier cosa que estemos escuchando y si no estamos de acuerdo con la situación política del país pues lo expresamos de alguna forma, con alguna inconformidad. Me parece un potencial para cuestionarse y para ponerse a reflexionar." 23

El relato anterior introduce otro de los sentidos a partir de los cuales los jóvenes se agrupan y actúan políticamente. Según sus opiniones, expresar lo que sienten y piensan genera posibilidades de reflexión en sí mismos y en los demás. Su expresión es el canal por el que comunican a los demás su inconformidad y la necesidad de reflexionar actos y pensamientos.

“[...] el arte tiene política en el sentido de la palabra,
porque es expresar ideas, es revelarse a que no me es-
cuchen y, más que a que no me escuchen a mí, es que no
escuchen a nadie, entonces ser uno de los que anime a
que escuchen a alguien. El arte se revela totalmente a la
negativa de escuchar a la gente". Es casi una necesidad
"expresar las cosas que yo tengo adentro, lo que yo pue-
do compartir a las demás personas y que pueden identi-
ficarse con eso; eso es lo primordial, como desahogarme
de los sentimientos, de pronto ayudar a construir algo
por medio de las frases -ese es un propósito-." ${ }^{24}$

Finalmente, otro de los sentidos que merece ser nombrado a causa de la importancia que otorga a las prácticas juveniles esté referido a la libertad. Sus prácticas tienen "potencial para trascender todas esas subyugaciones que tiene el individuo mismo, para que se desligue de todos esos tapujos que le crea la sociedad y no solo que la sociedad se los está creando en este momento, sino que ya viene con una carga de atrás" 25 . Liberarse de las ama-

23 Entrevista 2 Junio 2002.

24 Entrevista 2 Junio 2002.

25 Entrevista 4 Junio 2002. 
rras sociales, del egoísmo y de las tendencias discriminatorias es, para ellos, perspectivas y metas a alcanzar.

"Que la gente capte mediante la música que hacemos, capte y comprenda que la condición humana es una condición de libertad, de que no vivimos no en Colombia, ni que somos roqueros ni metaleros ni que somos chinos sino que somos humanos, que somos una especie general y que no es necesario hacer esas diferencias radicales que traen tanto tipo de consecuencias corrosivas en la sociedad. El sonido que nosotros hemos ido construyendo de cierta forma queremos que la gente, al escucharlo, se sienta tranquila y se sienta libre. Es como eso, que las personas, desde la música, sientan esa condición humana de libertad". ${ }^{26}$

Es claro que los ejercicios de poder que practican los jóvenes agrupados son completamente diferentes a los ejercicios políticos tradicionales. Ellos impugnan activamente los rasgos que caracterizan el poder formal, como la verticalidad, la obediencia, el individualismo, la corrupción y, sobre todo, la gran distancia que hay entre el discurso y las acciones de los funcionarios y políticos de turno.

“[...] no porque no nos interese la política, es porque a nosotros no nos interesa el poder desde ese lugar u ocupar ese lugar de poder; tal vez sí nos interese ocupar un lugar de poder, pero desde otro lugar, desde otro punto de vista y haciendo otro tipo de cosas; pero consideramos que podemos hacer cosas así no seamos concejales o alcaldes". ${ }^{27}$

Para estos jóvenes, las repercusiones de sus actos pueden ser grandes, a pesar de no ser alcaldes ni concejales. Sus búsquedas los ubican en lugares de poder resignificados y diferentes a los convencionales.

26 Entrevista 1 Junio 2002.

27 Entrevista 7 Enero 2006. 


\section{Comentarios finales}

La investigación formativa realizada por jóvenes sobre jóvenes del Oriente Antioqueño Cercano pretendía conocer si era posible tender puentes entre los movimientos y organizaciones juveniles y las entidades encargadas del diseño y ejecución de las políticas públicas de juventud. El propósito enfrentó a los investigadores a dos realidades: una relacionada con el mundo adulto, que estigmatiza y homogeniza la condición de la juventud de la zona, restringiendo su reconocimiento y valoración, y limitando sus espacios de acción. La otra realidad es la de los mismos jóvenes y las experiencias de vida que van configurando al enfrentar los desafíos que el contexto les presenta.

Desde el plano de los jóvenes, la investigación devela diversas formas de operar en la realidad, modalidades que, de una manera muy sintética, podríamos reunir en dos trayectorias que se contraponen. Una de ellas se caracteriza por asumir la juventud como una transitoriedad preparatoria $\mathrm{y}$, otra, como un tiempo de quehacer.

La transitoriedad preparatoria, que podría en algunos casos ser asimilada al concepto de "moratoria social", se caracteriza como un tiempo en el que el joven se sitúa frente a una serie de dispositivos sociales, culturales, políticos y económicos que le otorgan unos entornos, unos roles y unas oportunidades. Estas trayectorias juveniles caracterizadas por desarrollarse como tránsitos preparatorios para la vida adulta lleva a que los jóvenes se ubiquen en un limbo social y político, se normalicen con las ofertas institucionales, especialmente las escuelas y las dedicadas al bienestar de la niñez y de la juventud, generando en ellos aislamiento; porque se los sitúa en espacios sociales secundarios y ellos se acomodan en ámbitos marginales, donde realizan simulacros de participación, elección, representación y toma de decisiones, sin asumir responsabilidades sociales que los comprometan con acciones políticas de alguna incidencia. 
Estos ejercicios obligatorios, intrascendentes y marginales, realizados en escuelas, clubes juveniles de los institutos de bienestar familiar o en consejos municipales de juventud mantienen marginados a algunos jóvenes de los reales debates públicos y de la toma de posición y decisión frente a problemáticas que afectan su salud, seguridad social, empleo y educación. Muchos jóvenes de la región parecen acomodarse al anonimato, a la exclusión y a la invisibilización porque ello les permite sobrevivir en medio de una serie de conflictos en los ambientes familiares, escolares, barriales y municipales asegurando respuestas a intereses básicos.

Pero hay jóvenes que, desde la marginalidad y anonimato, les imponen los contextos regionales, se levantan contra la verticalidad, la exigencia de obediencia, el individualismo que propone el mercado, la corrupción promovida por los actores políticos y, sobre todo, develan la contradicción entre el discurso y las acciones de los adultos, sean estos maestros, funcionarios públicos, políticos de turno o actores armados. Esto implica que muchos jóvenes desarrollen procesos de empoderamiento juvenil con independencia y cierta autonomía de las instituciones o de las propuestas adultas, para no ser objeto de manipulación, de censura o desconocimiento de sus propuestas.

La condición de juventud, para estos, es un espacio y tiempo de quehacer, de hablar, de andar, de agruparse y de esperar activamente; por ello es que se empeñan, entre otras cosas, en indagar las realidades que los inquietan y en ganar mayores niveles de comprensión y de conocimiento para actuar. Pero este actuar es un accionar que se genera o genera procesos organizativos caracterizados por la ausencia de jerarquías y por rechazar activamente la verticalidad muy propia de las instituciones adultas. En la región estudiada, las organizaciones juveniles no institucionalizadas o formalizadas parecen caracterizarse por la reciprocidad entre los miembros, la compatibilidad en las relaciones y los afectos que aparecen como una de las razones por las cuales vale la pena permanecer agrupados. 
Los grupos informales y desinstitucionalizados son los espacios en los que es posible expresar lo que sienten y piensan, generando oportunidades de reflexión sobre sí mismos, los demás y los contextos de acción. Es en estas dinámicas, a lo largo de su permanencia en los grupos, que los jóvenes configuran y comparten sentidos políticos.

Los jóvenes que asumen esta trayectoria vital experimentan la condición de juventud como un tiempo de quehacer, que plantean y expresan con diferentes estrategias -teatro, música, periódicos, actividades culturales-; y es, en esa praxis social definida por diferentes dinámicas caracterizadas por la intersubjetividad, donde construyen y manifiestan activa y visceralmente sus desconfianzas sobre las formas tradicionales de ejercer poder.

Los sentidos, expresiones y proyecciones políticas de algunos jóvenes de la región no buscan tejer puentes. Por el contrario, subvierten y resignifican las representaciones e imágenes de las formas tradicionales y armadas de ejercer el poder. Por ello, no buscan afinidades o construir consensos con actores políticos tradicionales sino que deciden, de una manera que consideran autónoma e independiente, las acciones a realizar, los contextos y las formas de llevarlas a cabo. Si no hacen esto, este tipo de jóvenes se confinaría a la inactividad política y cultural o, como lo hacen otros, se someterían a los ejercicios de poder institucionales que tanto rechazan.

De la investigación realizada, podemos rescatar como potencialidad esos quehaceres juveniles organizados de manera alternativa; ellos son condición necesaria para el empoderamiento de los jóvenes en la región; desde la trayectoria vital de algunos jóvenes, la organización es un requisito esencial para configurar formas de participación efectiva y legítima, desde la autonomía y el reconocimiento.

La realidad de los jóvenes de la región cuestiona lo planteado desde miradas y categorías que pretenden homogenizar las 
diferentes trayectorias vitales juveniles, sus formas de vivenciar, hacer y decidir. Podemos pensar, a partir de la investigación, que los requerimientos básicos que posibilitan tender puentes, entre los movimientos y organizaciones juveniles de la región y las entidades encargadas del diseño y ejecución de las políticas públicas de juventud, son los de la participación efectiva, no solo discursiva o intelectual, y la inserción social real de los jóvenes en todos los espacios y momentos de los procesos sociales, económicos, políticos y culturales que afectan o responderán, de alguna manera, a su sistema de necesidades -diagnóstico, planeación, toma de decisiones, veeduría-; lo que llevaría a valorar y legitimar sus expectativas, experiencias, conocimientos y proyectos, además de reconocer los ambientes, prácticas y organizaciones donde ellos configuran sentidos políticos.

\section{Bibliografía consultada}

Arendt, Hannah (1974). La Condición Humana. Buenos Aires: Paidos.

Beck, Ulrich (1999). Hijos de la libertad. México: Fondo de cultura económica.

Beriain, Josetxo (1996). La integración en las sociedades modernas. Barcelona: Anthropos.

Feixa, Carles (1998). "Del reloj de arena al reloj digital". En: Jóvenes, revista de estudios sobre juventud. Año 7, Número 19; págs. 6-27. México: SEP, Instituto Mexicano de Juventud. Pp 256.

Krauskopf, Dina (2004). "Comprensión de la juventud, el ocaso de Moratoria psicosocial". En Revista de estudios sobre juventud. Jóvenes $\mathrm{N}^{\circ}$ 21, Julio Diciembre 2004, México, IMJ.

Margulis, Mario (Editor) (1998). La verde María Cristina. Viviendo a Toda: Jóvenes, Territorios Culturales y Nuevas Sensibilidades. Bogotá: Universidad Central, Siglo del Hombre Editores.

y Urresti, Marcelo (1998). “La construcción social de la condición de juventud". En, Margulis, Mario (Editor). La Verde María. Viviendo a Toda: Jóvenes, Territorios Culturales y Nuevas Sensibilidades. Bogotá: Universidad Central, Siglo del Hombre Editores.

Uribe Hincapié, María Teresa et al. (2000). "Desplazamiento forzado en Antioquia. Vol. 6: Oriente": Medellín, Universidad de Antio- 
Espacios y sentidos de la participación juvenil - A. Ghiso, P. Gaviria, N. Botero

quia, Instituto de Estudios Políticos y Secretariado Nacional de Pastoral Social, Conferencia Episcopal de Colombia. p. 10. Citado por: instituto de estudios Regionales Universidad de Antioquia.

http://www.disasterinfo.net/desplazados/_estaticos/informes/iner/De splazamientoforzadoOrienteAntioquenno.doc http://www. prensarural.org/ruben20031209a.htm. Abril 12 de 2006. 